\title{
Can multiple SNP testing in BRCA2 and BRCA1 female carriers be used to improve risk prediction models in conjunction with clinical assessment?
}

\author{
Mattia CF Prosperi ${ }^{1 *}$, Sarah L Ingham ${ }^{1}$, Anthony Howell ${ }^{2}$, Fiona Lalloo ${ }^{3}$, lain E Buchan ${ }^{1}$ and Dafydd Gareth Evans ${ }^{2,3}$
}

\begin{abstract}
Background: Several single nucleotide polymorphisms (SNPs) at different loci have been associated with breast cancer susceptibility, accounting for around $10 \%$ of the familial component. Recent studies have found direct associations between specific SNPs and breast cancer in BRCA1/2 mutation carriers. Our aim was to determine whether validated susceptibility SNP scores improve the predictive ability of risk models in comparison/conjunction to other clinical/demographic information.
\end{abstract}

Methods: Female BRCA1/2 carriers were identified from the Manchester genetic database, and included in the study regardless of breast cancer status or age. DNA was extracted from blood samples provided by these women and used for gene and SNP profiling. Estimates of survival were examined with Kaplan-Meier curves. Multivariable Cox proportional hazards models were fit in the separate BRCA datasets and in menopausal stages screening different combinations of clinical/demographic/genetic variables. Nonlinear random survival forests were also fit to identify relevant interactions. Models were compared using Harrell's concordance index (1 - c-index).

Results: 548 female BRCA1 mutation carriers and 523 BRCA2 carriers were identified from the database. Median Kaplan-Meier estimate of survival was 46.0 years (44.9-48.1) for BRCA1 carriers and 48.9 (47.3-50.4) for BRCA2. By fitting Cox models and random survival forests, including both a genetic SNP score and clinical/demographic variables, average 1 - c-index values were 0.221 (st.dev. 0.019) for BRCA1 carriers and 0.215 (st.dev. 0.018) for BRCA2 carriers.

Conclusions: Random survival forests did not yield higher performance compared to Cox proportional hazards. We found improvement in prediction performance when coupling the genetic SNP score with clinical/demographic markers, which warrants further investigation.

Keywords: Breast cancer, BRCA1, BRCA2, Single nucleotide polymorphism, Cox regression, Random survival forests, Survival analysis, Prognostic model, Concordance index

\section{Background}

$B R C A 1$ and $B R C A 2$ are major susceptibility genes that confer high lifetime risks for both breast and ovarian cancer. Deleterious mutations in these autosomal dominant cancer genes account for approximately $15-20 \%$ of the familial component of breast cancer [1-3]. The variable penetrance exhibited by these $B R C A$ mutations suggest other genetic factors to be present [4], and several studies have now identified a large number of breast

\footnotetext{
* Correspondence: mattia.prosperi@manchester.ac.uk

IInstitute of Population Health, Centre for Health Informatics, University of Manchester, Manchester, UK

Full list of author information is available at the end of the article
}

cancer susceptibility alleles [5-7]. Genome association studies had identified until recently 19 common variants at 18 loci that are associated with breast cancer susceptibility $[5,7]$ though the risk attributed to each of these single nucleotide polymorphisms (SNPs) are often modest and largely remain unexplained [6]. More recent studies into these polymorphisms have found direct associations between specific SNPs and breast cancer in $B R C A 1 / 2 \mathrm{mu}-$ tation carriers; TOX3, FGFR2, MAP3K, LSP1, 2q35, SLC4A7, 1p11.2, 5p12, 6q25.1 loci have all been associated with increased risk in breast cancer for BRCA2 mutation carriers [6,7]. Antoniou et al. [6] further determined TOX3, 2q35, and 6q25.1 were polymorphisms that 
increased risk for $B R C A 1$ mutation carriers. However, a recent study by Ingham et al. [8] found the 18 validated breast cancer susceptibility SNPs do not differentiate the risks of breast cancer in those with $B R C A 1$ mutations.

Some genetic modifiers may in themselves influence breast cancer risk factors rather than be directly associated; such as the genetic component associated with high mammographic density [4,9]. A recent study by Mitchell et al. looking at mammographic density in 206 BRCA1 and BRCA2 carriers compared to non-carriers found a significant association between increased breast cancer risk and increasing density in $B R C A 1 / 2$ carriers [9].

Alongside risk factors with a genetic component there are several hormonal risk factors that are thought to be associated with breast cancer both among the general population and those with hereditary breast cancer [10]. Correlations have been made between changes in breast mitotic/apoptotic activity and alterations in hormone levels across the menstrual cycle, and that if the levels of oestrogen and progesterone are reduced then the risk of breast cancer is reduced $[11,12]$. Though some debate surrounds the association of these factors with breast cancer among $B R C A 1 / 2$ carriers, with studies finding an association only in BRCA1 mutation carriers [13] and other finding no association [12]. Modifiable factors, such as body mass index (BMI) are also thought to influence the risk of breast cancer. Obesity has a well-documented association with breast cancer in the general population, due to influence of biological pathways [14], and postmenopausal weight gain has been associated with increased risk among $B R C A$ carriers [15].

At present, several personalised risk prediction models have been developed using familial, demographic, clinical, laboratory, genetic information domains, with a few combinations thereof $[8,16-19]$, as for instance the Gail, BOADICEA or IBIS methods [20], as well as more specific studies as surveys on gene expression markers [21], and use of machine learning for predicting recurrence or re-defying subtypes [22,23].

The aim of this study was to determine whether validated susceptibility SNPs improve the predictive ability of risk models in conjunction and comparison to demographic and clinical information.

\section{Methods}

\section{Study population}

Patients included in this study were BRCA1 and BRCA2 female pathogenic mutation carriers ascertained from the Genetic Medicine department, St Mary's Hospital, Manchester, UK. This clinic is one of the largest specialist genetics departments within the UK, and all families with a history of breast or ovarian cancer within the North West region are referred. Patients were included in this study regardless of breast cancer status or age. Dates of birth were taken from the information collected at time of family referral to the genetics department. Cases of breast cancer were confirmed by means of hospital records or the North West Cancer Intelligence Service. Dates of last follow-up were either date of breast cancer diagnosis or date the woman was last in contact with the genetics department or other NHS service or date of death.

\section{Ethics statement}

This research has been performed in accordance with the Declaration of Helsinki. The NHS Health Research Authority, National Health Research Ethics Committee North West, Greater Manchester Central (Barlow House, 4. Minshull Street, Manchester, M1 3DZ), reviewed this study and gave ethical approval; the Research Ethics Committee reference number is $10 / \mathrm{H} 1008 / 24$, dated $11^{\text {th }}$ July 2013. Written informed consent was obtained from all study participants (none minor at the time of enrolment).

\section{DNA testing}

DNA was extracted from blood samples provided by women attending the genetic clinics, using DNA Sanger sequencing and multiplex ligation-dependent probe amplification analysis for gene and SNP profiling; BRCA1 and $B R C A 2$ mutations were identified as well as the presence of any of the 18 tested breast cancer SNPs. Overall breast cancer SNP risk scores were calculated for each woman using the methods as recorded in the article Ingham et al. [8].

\section{Statistical models}

The study population was stratified by BRCA type (1 or 2) and menopausal stage (ovulating vs. menopause). Incidence of breast cancer was calculated for the strata, as well as Kaplan-Meier [24] estimates of survival. Maineffect multivariable Cox proportional hazards (CPH) [25] models were fit in the separate $B R C A$ data sets and then in the menopausal stages. End-point was the time to cancer, censored by the current age (or loss to follow up, or death for other causes). Proportional hazards assumption was tested via weighted residuals [26]. Variables included in the analyses were (see Table 1): year of birth, Manchester score [27] (transformed using the inverse hyperbolic sine), BMI; parity; age of menarche; age of menopause; age of first full-term pregnancy; oral contraception usage; time of diagnosis of an ovarian cancer followed up by oophorectomy (if any); time of mastectomy (if any); SNPs rs614367, rs704010, rs713588, rs889312, rs909116, rs1011970, rs1156287, rs1562430, rs2981579, rs3757318, rs3803662, rs4973768, rs8009944, rs9790879, rs10995190, rs11249433, rs13387042, rs10931936, genetic predisposition score (GPS), calculated on the mentioned SNPs according to Ingham et al. [8] Missing values were preliminarily analysed by means of univariable $\mathrm{CPH}$, comparing Akaike information criterion (AIC) [28] and coefficient p- 
Table 1 List of variables used in the study (for both BRCA1 and BRCA2 populations), data types, and variable inclusion in Cox proportional hazards models (i) to (vi)

\begin{tabular}{|c|c|c|c|c|c|c|c|}
\hline Variable & Data type & Model (i) & Model (ii) & Model (iii) & Model (iv) & Model (v) & Model (vi) \\
\hline Genetic predisposition score (GPS) & Numeric & $\checkmark$ & $\checkmark$ & & & & $\checkmark$ \\
\hline Year of birth & Numeric & & $\checkmark$ & & $\checkmark$ & $\checkmark$ & $\checkmark$ \\
\hline Manchester score & $\begin{array}{l}\text { Numeric (inverse } \\
\text { hyperbolic sine scale) }\end{array}$ & & $\checkmark$ & & $\checkmark$ & $\checkmark$ & $\checkmark$ \\
\hline Body mass index (BMI) & Numeric & & $\checkmark$ & & $\checkmark$ & $\checkmark$ & $\checkmark$ \\
\hline Parity & $\begin{array}{l}\text { Quartiles }(q 1 \ldots q 4)+ \\
\text { missing category }\end{array}$ & & $\checkmark$ & & $\checkmark$ & $\checkmark$ & $\checkmark$ \\
\hline Age of menarche & $\begin{array}{l}\text { Quartiles (q1 ... q4) + } \\
\text { missing category }\end{array}$ & & $\checkmark$ & & $\checkmark$ & $\checkmark$ & $\checkmark$ \\
\hline Age of menopause & $\begin{array}{l}\text { Quartiles (q1 ... q4)+ } \\
\text { missing category }+ \\
\text { ovulating stratum }\end{array}$ & & $\checkmark$ & & $\checkmark$ & $\checkmark$ & $\checkmark$ \\
\hline Age of first full-term pregnancy & $\begin{array}{l}\text { Quartiles (q1 ... q4)+ } \\
\text { missing category }+ \\
\text { never had full term } \\
\text { pregnancy }\end{array}$ & & $\checkmark$ & & $\checkmark$ & $\checkmark$ & $\checkmark$ \\
\hline Oral contraception usage & Quartiles (q1 ... q4) & & $\checkmark$ & & $\checkmark$ & $\checkmark$ & $\checkmark$ \\
\hline Oophorectomy & Binary (yes vs. no) & & $\checkmark$ & & $\checkmark$ & $\checkmark$ & $\checkmark$ \\
\hline Mastectomy & Binary (yes vs. no) & & $\checkmark$ & & $\checkmark$ & $\checkmark$ & $\checkmark$ \\
\hline $\begin{array}{l}\text { Individual single nucleotide polymorphisms } \\
\text { (SNPs, rs614367, rs704010, rs713588, rs889312, } \\
\text { rs909116, rs1011970, rs } 1156287, \text { rs } 1562430, \\
\text { rs2981579, rs3757318, rs3803662, rs4973768, } \\
\text { rs8009944, rs9790879, rs 10995190, rs } 11249433, \\
\text { rs13387042, rs10931936) }\end{array}$ & Binary (yes vs. no) & & & $\checkmark$ & $\checkmark$ & & $\checkmark$ \\
\hline
\end{tabular}

values of models with median/modes imputation vs. stratification into quartiles and addition of a category for those values which were missing. The following $\mathrm{CPH}$ models were fit for each population stratum: (i) GPS; (ii) GPS + year of birth + Manchester score $+\mathrm{BMI}+$ parity + age of menarche + age of menopause + age of full-term pregnancy + oral contraception usage + oophorectomy + mastectomy; (iii) SNPs; (iv) SNPs + year of birth + Manchester score + BMI + parity + age of menarche + age of menopause + age of full-term pregnancy + oral contraception usage + oophorectomy + mastectomy; (v) year of birth + Manchester score + BMI + parity + age of menarche + age of menopause + age of full-term pregnancy + oral contraception usage + oophorectomy + mastectomy; (vi) all variables. CPH models (ii), (iii), (iv) and (vi) were featureselected using a forward/backward stepwise heuristic driven by AIC [29]. Nonlinear random survival forests (RSF) [30] were also fit on all variables to identify putative variable interactions (333 trees, choosing the log-rank splitting rule). Table 1 summarises which variables were used for each model. CPH and RSF were compared using the complementary value of Harrell's concordance index (1 - c-index) [31] and the area under the receiver operating characteristic (AUROC) [32], under a bootstrap-based (100 resampled sets, using the out-of-bag predictions) method of extrasample error estimation [33].
All analyses were carried out using the R software [34].

\section{Results}

The BRCA1 population included 548 subjects, whilst the $B R C A 2$ population 523 . Table 2 shows population characteristics stratified by $B R C A$ type and menopausal stage.

Incidence of breast cancer for all BRCA1 carriers was 321 events per 23,649 person-years of follow-up (PYFY), i.e. 0.014 (95\% confidence interval, CI 0.0120 .015$)$. It was 92/ 9,872 (0.009, 95\% CI 0.008-0.011) and 88/3,770 (0.023, 95\% CI 0.019-0.029) for menopause and ovulating strata, respectively. The median (95\% CI) Kaplan-Meier estimate of survival time to breast cancer was $46.0(44.9-48.1)$ years in the whole BRCA1 population, 53.7 (52.0-60.7) for menopause stratum, and 35.5 (32.9-38.3) for the ovulating population ( $\mathrm{p}<0.0001$, log-rank test). Women diagnosed with an ovarian cancer who underwent an oophorectomy had a higher survival probability than those who did not ( $\mathrm{p}<0.0001$, log-rank test). At age 50 years, probability (95\% CI) of survival was $0.82(0.70-0.96)$ for those who had oophorectomy (71 women, 12 breast cancer events), versus $0.34(0.30-0.39)$ for the others. At age 60 it was 0.59 (0.40-0.86) versus $0.19(0.15-0.24)$. There was one case of breast cancer after risk reducing mastectomy (out of 49 women operated). 
Table 2 Characteristics of the study population

Median (interquartile range) or $\mathrm{N}(\%)$

\begin{tabular}{|c|c|c|c|c|c|c|}
\hline \multirow{3}{*}{ Variable } & \multirow{2}{*}{\multicolumn{3}{|c|}{ BRCA1 }} & & & \\
\hline & & & & \multicolumn{3}{|c|}{ BRCA2 } \\
\hline & $\begin{array}{c}\text { Menopause } \\
(n=200)\end{array}$ & $\begin{array}{c}\text { Ovulating } \\
(n=113)\end{array}$ & All $(n=548)^{*}$ & $\begin{array}{c}\text { Menopause } \\
(n=195)\end{array}$ & Ovulating $(n=93)$ & All $(n=523)^{*}$ \\
\hline Year of birth & 1955 (1946-1962) & 1963 (1952-1979) & 1959 (1948-1969) & 1952 (1944-1959) & 1963 (1952-1971) & 1957 (1947-1966) \\
\hline Manchester score & $32(22.5-40)$ & $28(20-38)$ & $29(20-40.75)$ & $26(20-35)$ & $27(20-36)$ & $26(20-35)$ \\
\hline BMI & $\begin{array}{l}24.07(22.34- \\
28.18)\end{array}$ & $\begin{array}{l}22.52(21.39- \\
26.71)\end{array}$ & $\begin{array}{l}23.7(21.6475- \\
27.3125)\end{array}$ & $\begin{array}{l}25.12(22.52- \\
\quad 28.565)\end{array}$ & $\begin{array}{c}24.225(21.975- \\
27.02)\end{array}$ & $\begin{array}{c}24.84(22.355- \\
28.305)\end{array}$ \\
\hline Parity & $2(2-3)$ & $1(0-2)$ & $2(1-3)$ & $2(0-9)$ & $2(0-9)$ & $2(0-9)$ \\
\hline Age of menarche & $13(12-14.25)$ & $13(12-14)$ & $13(12-14)$ & $13(12-14)$ & $13(12-14)$ & $13(12-14)$ \\
\hline Age of menopause & $43(38-46)$ & $44(40-48)^{* *}$ & $43(39-47)^{* *}$ & $45(40.5-48.5)$ & $45(39.5-49.5)^{* *}$ & $45(40-49)^{* *}$ \\
\hline $\begin{array}{l}\text { Age of full-term } \\
\text { pregnancy }\end{array}$ & $24(21-28)$ & $23(20-26.25)$ & $24(21-28)$ & $24(21-28)$ & $23(20.25-27)$ & $24(21-28)$ \\
\hline $\begin{array}{c}\text { Oral contraception } \\
\text { usage }\end{array}$ & $5(1-10)$ & $7(2.75-11)$ & $5(2-10)$ & $5(1-10)$ & $5(1-10)$ & $5(1-10)$ \\
\hline $\begin{array}{c}\text { Genetic } \\
\text { predisposition score }\end{array}$ & $0.98(0.70-1.29)$ & $0.95(0.63-1.17)$ & $0.95(0.67-1.27)$ & $0.83(0.63-1.17)$ & $1.17(0.77-1.62)$ & $0.90(0.68-1.33)$ \\
\hline Oophorectomy & $70(35 \%)$ & $0(0 \%)$ & $71(12.96 \%)$ & $88(45.13 \%)$ & $0(0 \%)$ & $102(19.50 \%)$ \\
\hline Mastectomy & $35(17.5 \%)$ & 7 (6.19\%) & $49(8.94 \%)$ & 17 (9.74\%) & $0(0 \%)$ & $17(3.25 \%)$ \\
\hline $\begin{array}{c}\text { Time of observation } \\
\text { (years) }\end{array}$ & $\begin{array}{c}48.04(42.74- \\
53.76)\end{array}$ & $30.83(28.0-38.90)$ & $41.26(35.83-49.38)$ & $50.68(44.77-57.70)$ & $33.66(29.13-42.49)$ & $44.37(38.02-51.78)$ \\
\hline No. of events & $92(46.00 \%)$ & $88(77.88 \%)$ & $321(58.58 \%)$ & $105(53.85 \%)$ & $72(77.42 \%)$ & $323(61.76 \%)$ \\
\hline
\end{tabular}

*includes also women with unknown menopausal stage status.

** women may have had menopause after a breast cancer diagnosis.
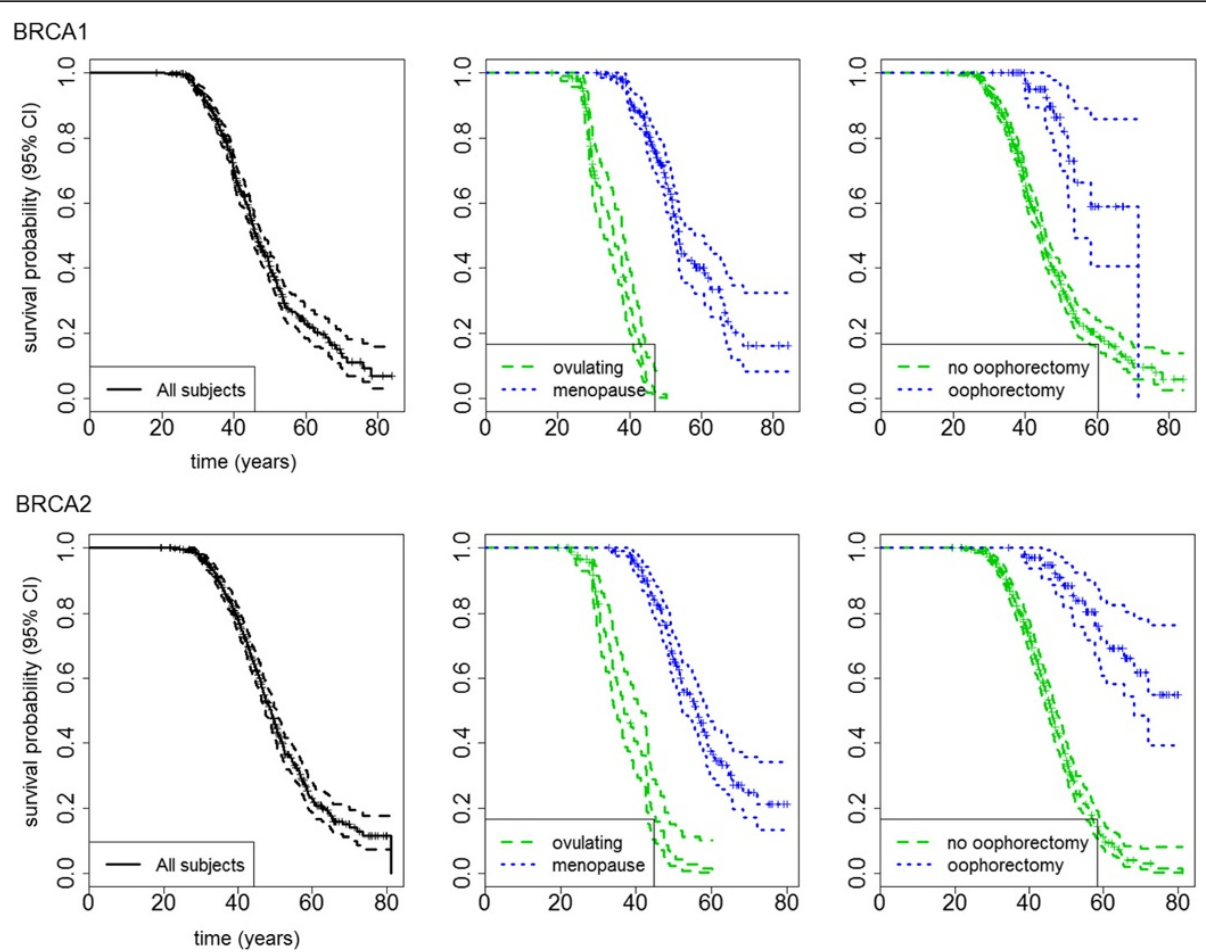

Figure 1 Kaplan-Meier estimates of being cancer-free for BRCA1 (upper panels) and BRCA2 (lower panels) carriers: overall, stratified by menopausal stage, and by oophorectomy. 
Incidence of cancer for all BRCA2 carriers was 323 events per 23,796 person-years of follow-up (PYFY), i.e. 0.014 (95\% confidence interval, CI 0.0120 .015 ). It was $105 / 10,120(0.010,95 \%$ CI $0.008-0.012)$ and 72/3,265 (0.022, 95\% CI 0.017-0.028) for menopause and ovulating strata, respectively. The median $(95 \% \mathrm{CI})$ Kaplan-Meier estimate of survival time was 48.9 (47.3-50.4) years in the whole BRCA2 population, 56.3 (52.3-58.7) for menopause stratum, and 36.8 (34.9-41.4) for the ovulating population ( $\mathrm{p}<0.0001$, log-rank test). Women who underwent an oophorectomy had a higher survival probability than those who did not ( $\mathrm{p}<0.0001$, log-rank test). At age 50 years, probability $(95 \% \mathrm{CI})$ of survival was 0.88 (0.82-0.95) for those who had oophorectomy (102 women, 23 breast cancer events), versus $0.34(0.30-0.40)$ for the others. At age 60 it was $0.70(0.59-0.83)$ versus $0.11(0.07-0.15)$. As in the $B R C A 1$ population, there was only one case of breast cancer after risk reducing mastectomy (out of 17 women operated). Figure 1 shows Kaplan-Meier graphs for the whole $B R C A 1 / 2$ population, for the menopausal stage strata, and for those who had/had not oophorectomy after the diagnosis of an ovarian cancer.

When applying models (i) through (vi) and RSF on the whole $B R C A 1$ population, using the out-of-bag estimator, average (st. dev.) 1 - c-index values of models were (see Table 3), respectively, 0.468 (0.037), 0.221 (0.019), 0.504 (0.026), 0.238 (0.019), 0.222 (0.019), 0.236 (0.018), 0.243 (0.019). When applying models (i) through (vi) and RSF on the whole BRCA2 population, using the out-of-bag estimator, average (st. dev.) 1 - cindex values of models were, respectively, 0.417 (0.021), 0.215 (0.018), 0.469 (0.028), 0.241 (0.019), 0.217 (0.018), 0.232 (0.019), 0.230 (0.019). The best model was therefore (ii), including GPS and clinical/demographic variables. The hypothesis of a lower difference in mean with respect to model (ii) for all other models could be rejected, except

Table 3 Average (st. dev.) 1 - c-index performance results of cox proportional hazards and random survival forest models as estimated by collating out-of-bag distributions from 100 bootstrap runs

\begin{tabular}{llc}
\hline Model & \multicolumn{1}{c}{ Average (st.dev.) } & $\mathbf{1}$ - c-index \\
\cline { 2 - 3 } & \multicolumn{1}{c}{ BRCA1 } & BRCA2 \\
\hline (i) GPS & $0.468(0.037)^{*}$ & $0.417(0.021)^{*}$ \\
(ii) GPS + Clin./Demogr. & $\mathbf{0 . 2 2 1 ( 0 . 0 1 9 )}$ & $\mathbf{0 . 2 1 5}(\mathbf{0 . 0 1 8})$ \\
(iii) SNPS & $0.504(0.026)^{*}$ & $0.469(0.028)^{*}$ \\
(iv) SNPs + Clin./Demogr. & $0.238(0.019)$ & $0.241(0.019)$ \\
(v) Clin./Demogr. & $0.222(0.019)$ & $0.217(0.018)$ \\
(vi) all variables (by AIC) & $0.236(0.018)$ & $0.232(0.019)$ \\
Random survival forest (all variables) & $0.243(0.019)$ & $0.230(0.019)$
\end{tabular}

${ }^{*} \mathrm{p}<0.0001$ as compared to model (ii) by an adjusted t-test. Values in bold show the best performance. for model (i) and (iii), which included only genetic variables (all p $<0.0001$ for both BRCA1 and BRCA2, Student's t-test corrected for sample overlap from multiple validation). Notably a re-calibrated SNP score, i.e. models (iii) and (iv), did not perform as well as the GPS. Consistent results were obtained by looking at the AUROC in the $1^{\text {st }}, 2^{\text {nd }}$ and $3^{\text {rd }}$ quartiles of observation times. The AUROC estimation was performed on a smaller out-ofbag sample (333 out-of-bag instances) for computational reasons. Figures 2 and 3 show c-index/AUROC graphs for $B R C A 1 / 2$ sets based on the out-of-bag estimator. Similar figures were obtained when stratifying for the menopausal stage (data not shown).

Tables 4 and 5 report relative hazards obtained by fitting Cox model (ii) on $B R C A 1$ and $B R C A 2$ populations, overall and stratified by menopausal stage. There was a calendar year of birth effect, increasing the risk of cancer for both $B R C A 1 / 2$ carrier cohorts ( $\mathrm{RH}$ ranging from 1.06 to $1.08, \mathrm{p}<0.0005$ across all strata). The Manchester score had a protective effect in the BRCA1 menopause stratum $(\mathrm{RH}=0.35, \mathrm{p}=0.0006)$ and showed the same trend in the whole $B R C A 1$ population $(\mathrm{RH}=0.8, \mathrm{p}=0.1)$, but the $\mathrm{RH}$ directions were not consistent across all strata as well as significance levels. The GPS score had a protective effect in the whole BRCA1 population and in the ovulating strata $(\mathrm{RH} 0.76 / 0.58, \mathrm{p}<0.015)$, and was associated to a higher hazard of breast cancer in the BRCA2 whole population $(\mathrm{RH}=1.33, \mathrm{p}=0.035)$.

The ovulating stratum (i.e. "not yet" in the menopausal stage as from Tables 4 and 5) had a higher hazard of breast cancer as compared to the first age quartile of the menopausal stage stratum (i.e. women entering the menopausal stage at $\sim 40$ years old). An early age of menopause (first age quartile, $\sim 40$ years old) was associated with a higher hazard of breast cancer as compared to an older age of menopause (yet a higher hazard than the ovulating stratum), consistently across all $B R C A 1 / 2$ carrier types, in the whole population and in the menopausal stage stratum. Note that menopause may be happening within the same year a chemotherapy was initiated right upon breast cancer diagnosis, resulting de facto in competing events (as diagnosis of menopause was given to the nearest year of age). Women who had either oophorectomy had a lower hazard as compared to those who had not (mastectomy could not be properly assessed due to the low number of events).

Finally, when fitting model (vi), i.e. feature-selected Cox regression using a forward/backward stepwise heuristic driven by AIC, for both $B R C A 1 / 2$ sets only the year of birth, all the menopausal age stages (along with ovulating stratum), and the oophorectomy variables were selected in the final model ( $\mathrm{RH}$ were in line with those obtained from other models). 


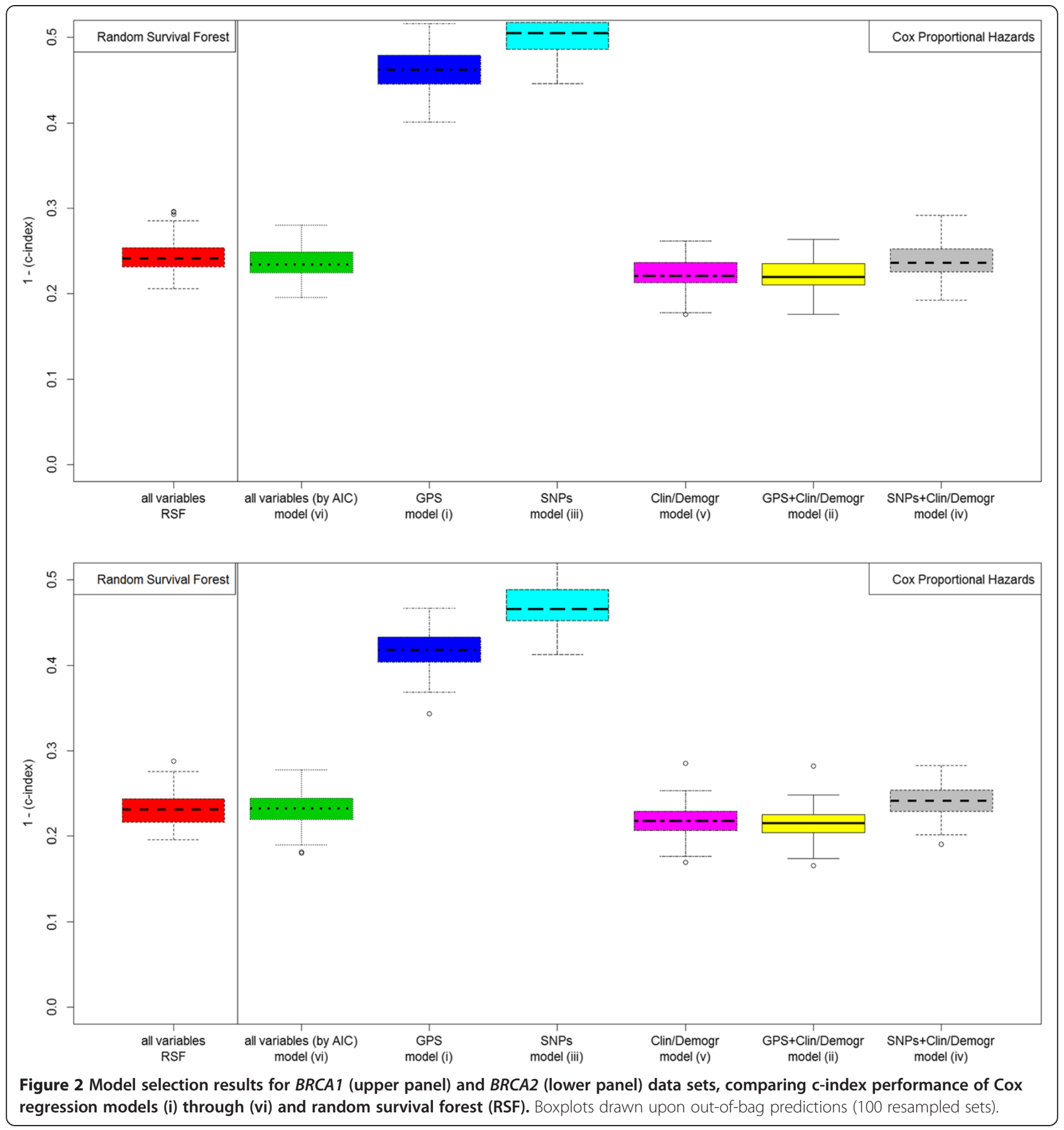

\section{Discussion}

In this study we applied a robust model selection framework composed of linear and non-linear statistical techniques for survival analysis, with the objective to test the predictive ability of existing risk scores for breast cancer in a population of $B R C A 1 / 2$ carriers, and to improve over the current state-of-the-art, from the models based on early genotyping and familial assessment to the most recent SNP scoring, trying to combine both clinical/ demographic information with high-resolution genetics. Also, we assessed the incidence and the determinants of breast cancer in the study population, and stratified the analyses by the menopausal status.

RSF did not yield higher performance as compared to $\mathrm{CPH}$, even if for some of the data sets the proportional hazard assumption was not met. Interestingly, the recalibration of GPS via the inclusion of SNPs in a CPH did not produce a better model fit (in terms of c-index 


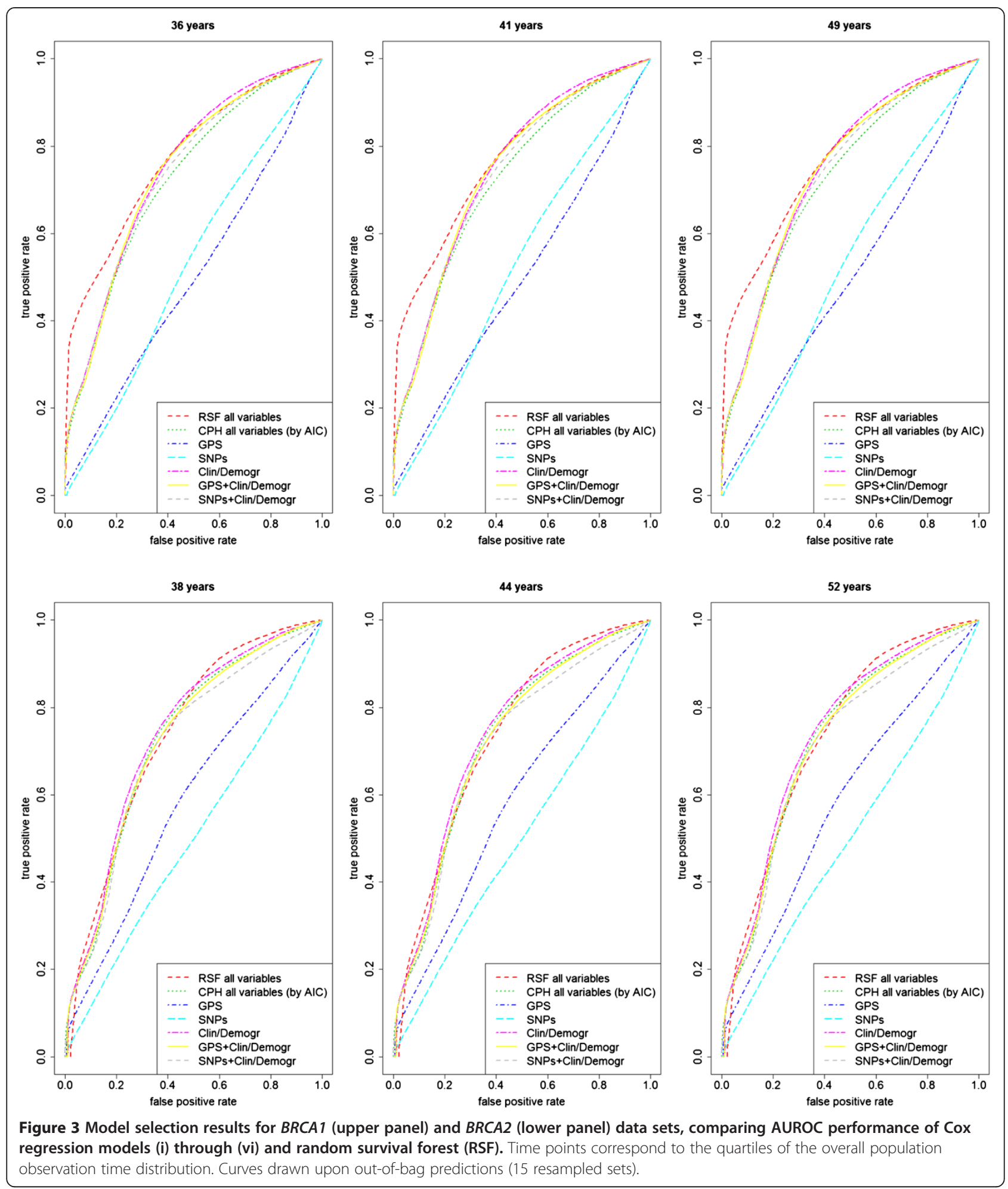

or AUROC) than using the original GPS in a CPH. In our case, the c-index estimation through out-of-bag distributions may be a conservative choice, but robust to over-training.
This study further highlights the predictive ability of GPS for BRCA2, showing an increased RH 1.33 (1.1-1.61) in the whole population, although not significant at the 0.05 level in the menopausal/ovulating stage strata. 
Table 4 Multivariable cox regression fit on BRCA1 data set, overall and stratified by menopausal stage, with covariate set based on model (ii)

\begin{tabular}{|c|c|c|c|c|c|c|}
\hline \multirow[b]{5}{*}{ Variable } & \multicolumn{6}{|c|}{ BRCA1 } \\
\hline & \multirow{3}{*}{\multicolumn{2}{|c|}{$\begin{array}{c}\text { All subjects } \\
\text { AIC }=3175 \\
\text { PH p-value }<0.0001\end{array}$}} & \multirow{3}{*}{\multicolumn{2}{|c|}{$\begin{array}{c}\text { Menopause } \\
\text { AIC }=765 \\
\text { PH p-value }=0.0111\end{array}$}} & \multirow{3}{*}{\multicolumn{2}{|c|}{$\begin{array}{c}\text { Ovulating } \\
\text { AIC }=591 \\
\text { PH p-value }=0.5040\end{array}$}} \\
\hline & & & & & & \\
\hline & & & & & & \\
\hline & $\mathrm{RH}(95 \% \mathrm{Cl})$ & p-value & $\mathrm{RH}(95 \% \mathrm{Cl})$ & p-value & $\mathrm{RH}(95 \% \mathrm{Cl})$ & p-value \\
\hline Year of birth & $1.06(1.05-1.08)$ & $<0.0001$ & $1.06(1.03-1.09)$ & $<0.0001$ & $1.08(1.04-1.11)$ & $<0.0001$ \\
\hline Manchester score & $0.8(0.61-1.05)$ & 0.1013 & $0.35(0.19-0.64)$ & 0.0006 & $1.56(0.83-2.91)$ & 0.1635 \\
\hline GPS & $0.76(0.61-0.95)$ & 0.0151 & $0.88(0.54-1.45)$ & 0.6248 & $0.58(0.37-0.9)$ & 0.0148 \\
\hline BMI & $1.02(0.98-1.06)$ & 0.3942 & $1.01(0.94-1.07)$ & 0.844 & $1.13(1.02-1.25)$ & 0.0229 \\
\hline Parity q2 vs. q1 & $1.32(0.91-1.89)$ & 0.1389 & $1.99(0.91-4.37)$ & 0.0846 & $0.72(0.32-1.63)$ & 0.4298 \\
\hline Parity q3 vs. q1 & $1.21(0.8-1.82)$ & 0.377 & $1.24(0.52-2.96)$ & 0.6246 & $0.85(0.36-2.04)$ & 0.7228 \\
\hline Parity q4 vs. q1 & $1.61(1.01-2.56)$ & 0.046 & $1.88(0.65-5.44)$ & 0.2434 & $1.21(0.43-3.4)$ & 0.724 \\
\hline Parity missing vs. q1 & $1.22(0.43-3.52)$ & 0.7066 & N/A & N/A & $3.16(0.34-28.9)$ & 0.3089 \\
\hline Age of menarche q2 vs. q1 & $1.17(0.82-1.67)$ & 0.3914 & $1.14(0.58-2.26)$ & 0.6979 & $0.43(0.17-1.07)$ & 0.0695 \\
\hline Age of menarche q3 vs. q1 & $1.02(0.67-1.54)$ & 0.9345 & $1.02(0.45-2.32)$ & 0.9638 & $0.87(0.45-1.71)$ & 0.6918 \\
\hline Age of menarche q4 vs. q1 & $0.82(0.55-1.23)$ & 0.3437 & $1.34(0.71-2.54)$ & 0.3682 & $0.94(0.4-2.16)$ & 0.8772 \\
\hline Age of menarche missing vs. q1 & $1.12(0.71-1.74)$ & 0.6307 & $2.63(0.86-8.03)$ & 0.0902 & $1.49(0.58-3.81)$ & 0.4094 \\
\hline Age of menopause q2 vs. q1 & $0.37(0.19-0.72)$ & 0.0036 & $0.19(0.09-0.43)$ & $<0.0001$ & & \\
\hline Age of menopause q3 vs. q1 & $0.39(0.22-0.7)$ & 0.0015 & $0.21(0.1-0.45)$ & $<0.0001$ & & \\
\hline Age of menopause q4 vs. q1 & $0.33(0.18-0.6)$ & 0.0003 & $0.13(0.06-0.28)$ & $<0.0001$ & & \\
\hline Age of menopause missing vs. q1 & $0.64(0.39-1.04)$ & 0.0708 & & & & \\
\hline Age of menopause not yet* vs. q1 & $4.48(2.74-7.33)$ & $<0.0001$ & & & & \\
\hline Age of full-term pregnancy q2 vs. q1 & $1.22(0.87-1.71)$ & 0.2594 & $1.96(0.98-3.91)$ & 0.0576 & $1.06(0.45-2.49)$ & 0.8908 \\
\hline Age of full-term pregnancy q3 vs. q1 & $1.37(0.96-1.96)$ & 0.079 & $2.01(0.94-4.32)$ & 0.0734 & $2.06(0.97-4.38)$ & 0.0615 \\
\hline Age of full-term pregnancy q4 vs. q1 & $1.22(0.81-1.84)$ & 0.3512 & $2.8(1.16-6.76)$ & 0.0221 & $0.95(0.34-2.64)$ & 0.9163 \\
\hline Age of full-term pregnancy missing vs. q1 & $1.11(0.7-1.79)$ & 0.652 & $1.31(0.45-3.8)$ & 0.6245 & $0.98(0.34-2.83)$ & 0.9744 \\
\hline Age of full-term pregnancy not yet** vs. q1 & $2.17(0.98-4.79)$ & 0.0552 & N/A & N/A & $2.69(0.77-9.34)$ & 0.1198 \\
\hline Oral contraception usage q2 vs. q1 & $0.64(0.39-1.04)$ & 0.0704 & $0.4(0.18-0.9)$ & 0.0263 & $1.14(0.39-3.33)$ & 0.8105 \\
\hline Oral contraception usage q3 vs. q1 & $1.07(0.71-1.62)$ & 0.7575 & $0.48(0.23-1)$ & 0.0495 & $4.77(1.77-12.83)$ & 0.002 \\
\hline Oral contraception usage q4 vs. q1 & $1(0.65-1.54)$ & 0.9936 & $0.98(0.46-2.07)$ & 0.9571 & $2.13(0.82-5.54)$ & 0.1211 \\
\hline Oral contraception usage missing vs. q1 & $1.1(0.72-1.66)$ & 0.6686 & $0.4(0.19-0.87)$ & 0.0207 & $3.94(1.42-10.94)$ & 0.0084 \\
\hline Mastectomy & $0.04(0.01-0.31)$ & 0.0018 & $0.05(0.01-0.39)$ & 0.0044 & N/A & N/A \\
\hline Oophorectomy & $0.31(0.16-0.58)$ & 0.0003 & $0.3(0.15-0.62)$ & 0.0012 & N/A & N/A \\
\hline
\end{tabular}

$\mathrm{N} / \mathrm{A}$ : could not be fit in the model; q1 ... q4: first to fourth age quartile, with the first being the youngest ( 40 years old); ${ }^{*}$ Ovulating; ${ }^{*}$ Never had full term pregnancy.

Instead, for $B R C A 1$ the effect of GPS was protective $(\mathrm{RH}=$ $0.76, \mathrm{p}=0.01$ ) in the whole $B R C A 1$ population and in the ovulating stage stratum (also protective but not significant at the 0.05 level in the menopausal stratum). Previous findings of Ingham et al. [8] already pointed out the predictive ability of 18 SNP GPS in BRCA2 but not BRCA1 carriers. This significant association of GPS however was not supported when fitting the stepwise models, retaining only the year of birth, the menopausal stage and the oophorectomy variables (across all carrier types and strata). The age cohort and oophorectomy had been previously associated with increased and decreased risk of breast cancer, respectively
$[35,36]$. We found that an later ages of menopause have a lower hazard of breast cancer as compared to the first age quartile, 40 years old, which seems in contradiction with previous results by Tyrer et al. [18], and being on the ovulating stratum has a higher hazard than experiencing early menopause. This is likely a model artefact, because the menopause may happen (being induced) right after to the initiation of a chemotherapy (i.e. competing events), and the menopause age is given to the nearest year. In any case, as women entering the menopausal stage early may be subject to treatment for preserving fertility, this warrants further investigation including a number of potential confounders. 
Table 5 Multivariable cox regression fit on BRCA2 data set, overall and stratified by menopausal stage, with covariate set based on model (ii)

\begin{tabular}{|c|c|c|c|c|c|c|}
\hline \multirow[b]{5}{*}{ Variable } & \multicolumn{6}{|c|}{ BRCA2 } \\
\hline & \multirow{3}{*}{\multicolumn{2}{|c|}{$\begin{array}{c}\text { All subjects } \\
\text { AIC }=3137 \\
\text { PH p-value }=0.03497\end{array}$}} & \multirow{3}{*}{\multicolumn{2}{|c|}{$\begin{array}{c}\text { Menopause } \\
\text { AIC }=881 \\
\text { PH p-value }=0.00125\end{array}$}} & \multirow{3}{*}{\multicolumn{2}{|c|}{$\begin{array}{c}\text { Ovulating } \\
\text { AIC }=475 \\
\text { PH p-value }=0.11892\end{array}$}} \\
\hline & & & & & & \\
\hline & & & & & & \\
\hline & RH $(95 \% \mathrm{Cl})$ & $\overline{p \text {-value }}$ & RH $(95 \% \mathrm{Cl})$ & $\overline{p \text {-value }}$ & RH $(95 \% \mathrm{Cl})$ & $\overline{p \text {-value }}$ \\
\hline Year of birth & $1.07(1.05-1.08)$ & $<0.0001$ & $1.07(1.04-1.11)$ & $<0.0001$ & $1.06(1.02-1.09)$ & 0.0005 \\
\hline Manchester score & $1.04(0.76-1.43)$ & 0.8048 & $1(0.61-1.65)$ & 0.9862 & $1.49(0.56-3.98)$ & 0.4228 \\
\hline GPS & $1.33(1.1-1.61)$ & 0.0038 & $1.33(0.93-1.91)$ & 0.119 & $0.88(0.51-1.51)$ & 0.6416 \\
\hline BMl & $0.99(0.94-1.03)$ & 0.5491 & $0.99(0.92-1.06)$ & 0.6694 & $1.03(0.92-1.16)$ & 0.5714 \\
\hline Parity q2 vs. q1 & $0.9(0.66-1.24)$ & 0.5307 & $1.4(0.73-2.67)$ & 0.3096 & $1.06(0.38-2.99)$ & 0.9083 \\
\hline Parity q3 vs. q1 & $0.89(0.6-1.34)$ & 0.5817 & $1.01(0.46-2.21)$ & 0.9808 & $1.51(0.36-6.31)$ & 0.5705 \\
\hline Parity q4 vs. q1 & $0.78(0.47-1.28)$ & 0.3182 & $0.9(0.38-2.13)$ & 0.8112 & $1.32(0.34-5.12)$ & 0.6914 \\
\hline Parity missing vs. q1 & $0.15(0.06-0.38)$ & $<0.0001$ & N/A & N/A & N/A & N/A \\
\hline Age of menarche q2 vs. q1 & $1.36(0.94-1.97)$ & 0.1007 & $2.53(1.47-4.35)$ & 0.0008 & $1.57(0.64-3.84)$ & 0.3251 \\
\hline Age of menarche $q 3$ vs. q1 & $1.39(0.94-2.07)$ & 0.0984 & $1.76(0.95-3.27)$ & 0.0742 & $2.43(0.92-6.45)$ & 0.074 \\
\hline Age of menarche $q 4$ vs. q1 & $1.25(0.83-1.88)$ & 0.2822 & $1.51(0.83-2.76)$ & 0.1803 & $2.03(0.79-5.25)$ & 0.1422 \\
\hline Age of menarche missing vs. q1 & $2.32(1.43-3.78)$ & 0.0007 & $1.54(0.18-13.15)$ & 0.6947 & $1.06(0.24-4.81)$ & 0.9362 \\
\hline Age of menopause q2 vs. q1 & $1.16(0.64-2.1)$ & 0.6161 & $0.76(0.39-1.48)$ & 0.4188 & & \\
\hline Age of menopause q3 vs. q1 & $0.91(0.51-1.63)$ & 0.7511 & $0.63(0.34-1.17)$ & 0.1429 & & \\
\hline Age of menopause q4 vs. q1 & $0.9(0.48-1.69)$ & 0.7391 & $0.67(0.33-1.37)$ & 0.2762 & & \\
\hline Age of menopause missing vs. q1 & $1.03(0.59-1.8)$ & 0.9114 & & & & \\
\hline Age of menopause not yet* vs. q1 & $4.11(2.41-7.01)$ & $<0.0001$ & & & & \\
\hline Age of full-term pregnancy q2 vs. q1 & $1.55(1.1-2.2)$ & 0.0133 & $1.52(0.82-2.81)$ & 0.1825 & $1.96(0.69-5.57)$ & 0.2043 \\
\hline Age of full-term pregnancy q3 vs. q1 & $1.03(0.71-1.49)$ & 0.8902 & $0.94(0.48-1.85)$ & 0.8659 & $1.61(0.62-4.19)$ & 0.327 \\
\hline Age of full-term pregnancy q4 vs. q1 & $0.91(0.62-1.33)$ & 0.6154 & $1.96(1.01-3.8)$ & 0.0471 & $0.6(0.21-1.71)$ & 0.3371 \\
\hline Age of full-term pregnancy missing vs. q1 & $1.43(0.95-2.15)$ & 0.0822 & $1.16(0.46-2.88)$ & 0.7546 & $2.64(0.68-10.25)$ & 0.161 \\
\hline Age of full-term pregnancy not yet** vs. q1 & $16.5(5.32-51.21)$ & $<0.0001$ & N/A & N/A & $19.2(3.57-103.1)$ & 0.0006 \\
\hline Oral contraception usage q2 vs. q1 & $1(0.64-1.54)$ & 0.9822 & $1.29(0.67-2.48)$ & 0.4473 & $0.84(0.31-2.25)$ & 0.7241 \\
\hline Oral contraception usage q3 vs. q1 & $1.67(1.11-2.5)$ & 0.0129 & $1.8(0.94-3.46)$ & 0.0774 & $1.45(0.58-3.63)$ & 0.4289 \\
\hline Oral contraception usage q4 vs. q1 & $1.34(0.85-2.1)$ & 0.2049 & $1.95(0.92-4.11)$ & 0.0814 & $0.85(0.3-2.4)$ & 0.7582 \\
\hline Oral contraception usage missing vs. q1 & $1.08(0.71-1.63)$ & 0.7282 & $0.9(0.46-1.74)$ & 0.7472 & $1.44(0.58-3.59)$ & 0.4294 \\
\hline Mastectomy & $0.05(0.01-0.39)$ & 0.0038 & N/A & N/A & N/A & N/A \\
\hline Oophorectomy & $0.18(0.11-0.29)$ & $<0.0001$ & $0.22(0.13-0.38)$ & $<0.0001$ & N/A & $\mathrm{N} / \mathrm{A}$ \\
\hline
\end{tabular}

N/A: could not be fit in the model; q1 ... q4: first to fourth quartile, with the first being the youngest ( 40 years old); *ovulating; **never had full term pregnancy

Limitations of this study are in the usage of the cindex as a measure of model performance, which presents a series of flaws [37-39], although our results were confirmed using the AUROC estimator. Alternative measures have been presented, like prediction error curves [40] that may be employed as additional indicators. Another limitation is that we did not fit the Cox models using time-updated covariates (as for menopausal stage or age of menarche, for instance) and this may dilute their effect across all time, instead of calculating the hazard on specific time intervals.

\section{Conclusions}

We exploited model selection in machine learning towards the personalised diagnosis of breast cancer, incorporating different domains of information including genetics, clinical, and demographics. Given the improvement in prediction performance obtained by coupling a genetic progression score with clinical and demographic markers, further investigation for identifying both genetic and non-genetic factors (along with their interactions in terms of epigenetics) is warranted. 


\section{Competing interests}

The authors declare that they have no competing interests.

\section{Authors' contributions}

MCFP statistical modelling, manuscript writing; SI data preparation, statistical analysis, manuscript writing; IEB statistical review, manuscript review; DGE patient identification, statistical review, manuscript writing; $\mathrm{AH}$ and FL patient identification, manuscript writing. All authors read and approved the final manuscript.

\section{Acknowledgments}

This study was funded by an NIHR programme grant (RP-PG-0707-10031). SNP testing was funded through the Genesis breast cancer prevention appeal. DGE receives support through the NIHR Manchester BRC and is an NIHR Clinical Senior Investigator. We also acknowledge the University of Manchester's Health eResearch Centre (HeRC) funded by the MRC grant MR/K006665/1. The study sponsor(s) had no role in study design; collection, analysis and interpretation of data; writing of the report or in the decision to submit for publication.

\section{Author details}

'Institute of Population Health, Centre for Health Informatics, University of Manchester, Manchester, UK. ${ }^{2}$ Genesis Prevention Centre, University Hospital of South Manchester, Manchester, UK. ${ }^{3}$ Department of Genetic Medicine, Manchester Academic Health Science Centre, St. Mary's Hospital, University of Manchester, Manchester, UK.

Received: 3 June 2014 Accepted: 25 September 2014 Published: 1 October 2014

\section{References}

1. Mavaddat N, Antoniou AC, Easton DF, Garcia-Closas M: Genetic susceptibility to breast cancer. Molecular oncology 2010, 4(3):174-191.

2. Couch FJ, Wang X, McGuffog L, Lee A, Olswold C, Kuchenbaecker KB, Soucy P, Fredericksen Z, Barrowdale D, Dennis J, Gaudet MM, Dicks E, Kosel M, Healey S, Sinilnikova OM, Lee A, Bacot F, Vincent D, Hogervorst FB, Peock S, StoppaLyonnet D, Jakubowska A, KConFab Investigators, Radice P, Schmutzler RK, SWE-BRCA, Domchek SM, Piedmonte M, Singer CF, Friedman E, et al: Genomewide association study identifies novel breast cancer susceptibility loci. Nature 2007, 447(7148):1087-1093.

3. Stacey SN, Manolescu A, Sulem P, Rafnar T, Gudmundsson J, Gudjonsson SA, Masson G, Jakobsdottir M, Thorlacius S, Helgason A, Aben KK, Strobbe L, AlbersAkkers MT, Swinkels DW, Henderson BE, Kolonel LN, Le Marchand L, Millastre E, Andres R, Godino J, Garcia-Prats MD, Polo E, Tres A, Mouy M, Saemundsdottir J, Backman VM, Gudmundsson L, Kristjansson K, Bergthorsson JT, Kostic J, et al: Common variants on chromosomes $2 \mathrm{q} 35$ and $16 \mathrm{q} 12$ confer susceptibility to estrogen receptor-positive breast cancer. Nat Genet 2007, 39(7):865-869.

4. Chenevix-Trench G, Milne RL, Antoniou AC, Couch FJ, Easton DF, Goldgar $D E$, Cimba: An international initiative to identify genetic modifiers of cancer risk in BRCA1 and BRCA2 mutation carriers: the Consortium of Investigators of Modifiers of BRCA1 and BRCA2 (CIMBA). Breast cancer research: BCR 2007, 9(2):104.

5. Turnbull C, Ahmed S, Morrison J, Pernet D, Renwick A, Maranian M, Seal S, Ghoussaini M, Hines S, Healey CS, Hughes D, Warren-Perry M, Tapper W, Eccles D, Evans DG, Breast Cancer Susceptibility Collaboration (UK), Hooning M, Schutte M, van den Ouweland A, Houlston R, Ross G, Langford C, Pharoah PD, Stratton MR, Dunning AM, Rahman N, Easton DF: Genome-wide association study identifies five new breast cancer susceptibility loci. Nat Genet 2010, 42(6):504-507.

6. Antoniou AC, Beesley J, McGuffog L, Sinilnikova OM, Healey S, Neuhausen SL, Ding YC, Rebbeck TR, Weitzel JN, Lynch HT, Isaacs C, Ganz PA, Tomlinson G, Olopade OI, Couch FJ, Wang X, Lindor NM, Pankratz VS, Radice P, Manoukian S, Peissel B, Zaffaroni D, Barile M, Viel A, Allavena A, Dall'Olio V, Peterlongo P, Szabo Cl, Zikan M, Claes K: Common breast cancer susceptibility alleles and the risk of breast cancer for BRCA1 and BRCA2 mutation carriers: implications for risk prediction. Cancer Res 2010, 70(23):9742-9754.

7. Antoniou AC, Kartsonaki C, Sinilnikova OM, Soucy P, McGuffog L, Healey S, Lee A, Peterlongo P, Manoukian S, Peissel B, Zaffaroni D, Cattaneo E, Barile M, Pensotti V, Pasini B, Dolcetti R, Giannini G, Putignano AL, Varesco L, Radice P, Mai PL, Greene MH, Andrulis IL, Glendon G, Ozcelik H, Thomassen M, Gerdes AM, Kruse TA, Birk
Jensen U, Crüger DG, et al: Common alleles at 6q25.1 and 1p11.2 are associated with breast cancer risk for BRCA1 and BRCA2 mutation carriers. Hum Mol Genet 2011, 20(16):3304-3321.

8. Ingham SL, Warwick J, Byers H, Lalloo F, Newman WG, Evans DG: Is multiple SNP testing in BRCA2 and BRCA1 female carriers ready for use in clinical practice? Results from a large Genetic Centre in the UK. Clin Genet 2013, 84(1):37-42.

9. Mitchell G, Antoniou AC, Warren R, Peock S, Brown J, Davies R, Mattison J, Cook M, Warsi I, Evans DG, Eccles D, Douglas F, Paterson J, Hodgson S, Izatt L, Cole T, Burgess L, Eeles R, Easton DF: Mammographic density and breast cancer risk in BRCA1 and BRCA2 mutation carriers. Cancer Res 2006, 66(3):1866-1872.

10. Chang-Claude J, Andrieu N, Rookus M, Brohet R, Antoniou AC, Peock S, Davidson R, Izatt L, Cole T, Noguès C, Luporsi E, Huiart L, Hoogerbrugge N, Van Leeuwen FE, Osorio A, Eyfjord J, Radice P, Goldgar DE, Easton DF, Epidemiological Study of Familial Breast Cancer (EMBRACE), Gene Etude Prospective Sein Ovaire (GENEPSO), Genen Omgeving studie van de werkgroep Hereditiair Borstkanker Onderzoek Nederland (GEO-HEBON), International BRCA1/2 Carrier Cohort Study (IBCCS) collaborators group: Age at menarche and menopause and breast cancer risk in the international BRCA1/2 carrier cohort study. Cancer Epidemiol Biomarkers Prev 2007, 16(4):740-746.

11. Ferguson DJ, Anderson TJ: Morphological evaluation of cell turnover in relation to the menstrual cycle in the "resting" human breast. Br J Cancer 1981, 44(2):177-181.

12. Pike MC, Spicer DV, Dahmoush L, Press MF: Estrogens, progestogens, normal breast cell proliferation, and breast cancer risk. Epidemiol Rev 1993, 15(1):17-35.

13. Kotsopoulos J, Lubinski J, Lynch HT, Neuhausen SL, Ghadirian P, Isaacs C, Weber B, Kim-Sing C, Foulkes WD, Gershoni-Baruch R, Ainsworth P, Friedman E, Daly M, Garber JE, Karlan B, Olopade OI, Tung N, Saal HM, Eisen A, Osborne M, Olsson H, Gilchrist D, Sun P, Narod SA: Age at menarche and the risk of breast cancer in BRCA1 and BRCA2 mutation carriers. Cancer causes \& control: CCC 2005, 16(6):667-674.

14. Guinan EM, Hussey J, McGarrigle SA, Healy LA, O'Sullivan JN, Bennett K, Connolly EM: A prospective investigation of predictive and modifiable risk factors for breast cancer in unaffected BRCA1 and BRCA2 gene carriers. BMC Cancer 2013, 13:138.

15. Manders P, Pijpe A, Hooning MJ, Kluijt I, Vasen HF, Hoogerbrugge N, van Asperen CJ, Meijers-Heijboer H, Ausems MG, van Os TA, Gomez-Garcia EB, Brohet RM HEBON, van Leeuwen FE, Rookus MA: Body weight and risk of breast cancer in BRCA1/2 mutation carriers. Breast Cancer Res Treat 2011, 126(1):193-202.

16. Gorfine M, Hsu L, Parmigiani G: Frailty models for familial risk with application to breast cancer. J Am Stat Assoc 2013, 108(504):1205-1215.

17. Meads C, Ahmed I, Riley RD: A systematic review of breast cancer incidence risk prediction models with meta-analysis of their performance. Breast Cancer Res Treat 2012, 132(2):365-377.

18. Tyrer J, Duffy SW, Cuzick J: A breast cancer prediction model incorporating familial and personal risk factors. Stat Med 2004, 23(7):1111-1130.

19. Amir E, Freedman OC, Seruga B, Evans DG: Assessing women at high risk of breast cancer: a review of risk assessment models. J Natl Cancer Inst 2010, 102(10):680-691.

20. Lee AJ, Cunningham AP, Kuchenbaecker KB, Mavaddat N, Easton DF, Antoniou AC, Consortium of Investigators of Modifiers of B, Breast Cancer Association C: BOADICEA breast cancer risk prediction model: updates to cancer incidences, tumour pathology and web interface. $\mathrm{Br} J$ Cancer 2014, 110(2):535-545.

21. Yang X, Ai X, Cunningham JM: Computational prognostic indicators for breast cancer. Cancer Manag Res 2014, 6:301-312.

22. Faradmal J, Soltanian AR, Roshanaei G, Khodabakhshi R, Kasaeian A: Comparison of the performance of log-logistic regression and artificial neural networks for predicting breast cancer relapse. Asian Pacific journal of cancer prevention: APJCP 2014, 15(14):5883-5888.

23. Jahid MJ, Huang TH, Ruan J: A personalized committee classification approach to improving prediction of breast cancer metastasis. Bioinformatics 2014, 30(13):1858-1866.

24. Kaplan EL, Meier P: Nonparametric-estimation from incomplete observations. J Am Stat Assoc 1958, 53(282):457-481.

25. Cox DR: Regression models and life-tables. J Roy Stat Soc B 1972, 34(2):187-+. 
26. Grambsch PM, Therneau TM: Proportional hazards tests and diagnostics based on weighted residuals. Biometrika 1994, 81(3):515-526.

27. Evans DGR, Lalloo F, Wallace A, Rahman N: Update on the Manchester scoring system for BRCA1 and BRCA2 testing. J Med Genet 2005, 42(7):e39

28. Akaike H: New look at statistical-model identification. leee T Automat Contr 1974, Ac19(6):716-723.

29. Venables WN, Ripley BD: Modern Applied Statistics With S-PLUS. 3rd edition. New York: Springer; 1999

30. Ishwaran H, Kogalur UB, Blackstone EH, Lauer MS: Random survival forests. Ann Appl Stat 2008, 2(3):841-860.

31. Harrell FE, Califf RM, Pryor DB, Lee KL, Rosati RA: Evaluating the yield of medical tests. Jama-J Am Med Assoc 1982, 247(18):2543-2546.

32. Heagerty PJ, Zheng YY: Survival model predictive accuracy and ROC curves. Biometrics 2005, 61(1):92-105.

33. Hastie T, Tibshirani R, Friedman JH: The Elements of Statistical Learning: Data Mining, Inference, and Prediction. 2nd edition. New York, NY: Springer; 2009.

34. R Core Team: R: A Language and Environment for Statistical Computing. Vienna, Austria: R Foundation for Statistical Computing; 2013.

35. Ocana-Riola R, Mayoral-Cortes JM, Navarro-Moreno E: Age-period-cohort effect on female breast cancer mortality in Southern Spain. Med Oncol 2013, 30(3):671.

36. Valachis A, Nearchou AD, Lind P: Surgical management of breast cancer in BRCA-mutation carriers: a systematic review and meta-analysis. Breast Cancer Res Treat 2014, 144(3):443-455.

37. Pencina MJ, D'Agostino RB: Overall $C$ as a measure of discrimination in survival analysis: model specific population value and confidence interval estimation. Stat Med 2004, 23(13):2109-2123.

38. Taktak AFG, Eleuteri A, Lake SP, Fisher AC: A web-based tool for the assessment of discrimination and calibration properties of prognostic models. Comput Biol Med 2008, 38(7):785-791.

39. Gonen M, Heller G: Concordance probability and discriminatory power in proportional hazards regression. Biometrika 2005, 92(4):965-970.

40. Mogensen UB, Ishwaran $H$, Gerds TA: Evaluating random forests for survival analysis using prediction error curves. J Stat Softw 2012, 50(11):1-23.

\section{doi:10.1186/1472-6947-14-87}

Cite this article as: Prosperi et al:: Can multiple SNP testing in BRCA2 and $B R C A 1$ female carriers be used to improve risk prediction models in conjunction with clinical assessment? BMC Medical Informatics and Decision Making 2014 14:87.

\section{Submit your next manuscript to BioMed Central and take full advantage of:}

- Convenient online submission

- Thorough peer review

- No space constraints or color figure charges

- Immediate publication on acceptance

- Inclusion in PubMed, CAS, Scopus and Google Scholar

- Research which is freely available for redistribution 